\title{
Is the brazilian diverse environment is a crib for the emergence and maintenance of exotic arboviruses?
}

\section{DANIELE B.A. MEDEIROS and PEDRO FERNANDO C. VASCONCELOS}

Department of Arbovirology and Hemorrhagic Fevers, Instituto Evandro Chagas, SVS/Ministry of Health, Rodovia BR 316, Km 07, s/n, 67030-000 Ananindeua, PA, Brazil

Manuscript received on April 5, 2019; accepted for publication on July 6, 2019

\begin{abstract}
How to cite: MEDEIROS DBA AND VASCONCELOS PFC. 2019. Is the brazilian diverse environment is a crib for the emergence and maintenance of exotic arboviruses? An Acad Bras Cienc 91: e20190407. DOI 10.1590/00013765201920190407.

Abstract: We review the potential of Amazon forest as a source for circulation and maintenance of native arboviruses as well its capacity to host exotic arboviruses introduced in Brazil during their process of adapting to the Amazon environment. After a brief introduction about arboviruses isolated in Amazon region and description of the main arboviruses pathogenic to humans, we highlight the history of the last two exotic viruses introduced in Brazil - Chikungunya virus (CHIKV) and Zika virus (ZIKV) - and their consequences to the public health. Finally, we discuss and hypothesize what will happen with them after the outbreak. We look to the past to predict the future.
\end{abstract}

Key words: arboviruses, new introduction, zika, chikungunya.

\section{BACKGROUND}

The Amazon forest is considered the world's most important ecological system, mainly because its rich biological diversity. Indeed, in the Amazon a plethora of plant, vertebrate, insect and microbial life-forms, and are vital for the functioning of the biosphere (Dirzo and Raven 2003). This environment has all necessary conditions to the maintenance of arboviruses, an ecologic group of viruses that are maintained in nature in complex cycles in which hematophagous arthropods act as vectors and vertebrate as hosts. In fact, these viruses are biologically transmitted by their vectors to susceptible vertebrate hosts during their blood

Correspondence to: Daniele Barbosa de Almeida Medeiros

E-mail: danielemedeiros@iec.gov.br

ORCid: https://orcid.org/0000-0001-5493-1618 meals. After transmission, vertebrate hosts develop high titers of viremia sufficient to infect subsequently uninfected feeding vectors. Importantly, vector infection is typically lifelong, with no apparent effects. Curiously, certain arboviruses have the capacity to be transmitted transovarially and venereally among their arthropod vectors (Darwish et al. 1985). It is interesting to observe that in general, each arbovirus has specific vector and host, however, others are more eclectic and have several potential vectors and hosts. On the other side, a same vector can transmit several arboviruses to specific or multiple hosts (Vasconcelos et al. 1992, 2001).

The most frequent hematophagous arthropods that may serve as arbovirus vectors include mosquitoes, ticks, sandflies, midges, and possibly mites. Two kind of vertebrate hosts are of particular 
importance: those that specifically serve as sources of vector infection and those that frequently are not capable to produce large virus titers, but in which overt disease may occur. From an epidemiological standpoint, the former are of primary interest, because together with the vector they are responsible for the maintenance of viruses, and moreover, can act as disseminators and amplifiers of arboviruses in nature. Humans are commonly dead-end hosts and their infection is usually a biological accident, or alternatively are typically tangential hosts for the virus (Vasconcelos et al. 2001). It is important to remember that the role of ecosystem itself is not well understood, but we have strong evidences that when alteration of the natural environment is favorable to the viruses, the result is an explosion of transmission that is frequently followed of adaptation of the virus to the urban environment, i.e. urbanization; however if the changes in the ecosystem are not favorable to the viruses, they will disappear (Vasconcelos et al. 1992, 2001).

\section{THE BEGINNING OF ARBOVIRUSES STUDIES IN AMAZON REGION}

Arbovirus studies conducted by Department of Arbovirology and Hemorrhagic Fevers (SAARB) of Evandro Chagas Institute (IEC) in many areas of the Brazilian Amazon region over the past seven decades have identified a large number of viruses. Indeed, up to 2018, around 220 different arboviruses species have been isolated and characterized (Vasconcelos et al. unpublished data), which is remarkable considering the reported number by the International Arboviruses Catalog (https://wwwn. cdc.gov/arbocat/VirusBrowser.aspx). Such large number of viruses is due, as previously mentioned, to the fact that this region contains an astounding diversity of both arthropods and terrestrial and arboreal vertebrates and an essentially endless variety of ecological conditions necessary for arbovirus maintenance (Vasconcelos et al. 2001,
Travassos da Rosa 2016), not to mention the efforts by energetic and enthusiastic personnel working at the IEC, in special conducted by Dr. Amélia P. A. Travassos da Rosa (Travassos da Rosa 2016).

From 1959 to 1998, Dr. Amélia Travassos da Rosa was in charge of SAARB/IEC team and conduced significant and relevant studies, including the antigenic characterization of new viral agents, developed experimental studies on the pathogenesis, ultra-structure, molecular and evolution of these agents, and as well as established an arbovirus collection with approximately 10,000 strains. In this period, the Amazon region biodiversity was positively explored to extract important information on the arboviruses and their relationship with Amazonian ecosystem. In outstanding studies it was also evaluated the impact of anthropic actions, such as deforestation, mining, and highway and hydroelectric powerplant constructions. These studies revealed the emergence of several arboviruses potentially pathogenic for humans. As example, after the Tucuruí hydroelectric dam construction in Tocantins river, Tucuruí municipality in Pará State, a large area of tropical forest were flooded and hundreds of virus strains were isolated, including 37 new ones to Brazil and four new to science (Dégallier et al. 1992, Travassos da Rosa et al. 1992, Travassos da Rosa 2016).

\section{SUMMARY OF PRINCIPAL FINDINGS FOR ARBOVIRUSES INFECTING HUMANS}

Outbreaks of febrile disease have provided opportunities to find arboviruses in humans and domestic animals. Many arboviruses have been emerging and re-emerging and causing epidemics in the Amazon region, such as: Oropouche virus (OROV), Mayaro virus (MAYV), Dengue virus (DENV) and Yellow Fever (YFV). DENV is associated with febrile exanthematic illness, in addition to its potential for causing hemorrhagic fever. MAYV is also associated with febrile 
exanthematic disease and important arthritis and myalgia. YFV is the only arboviral hemorrhagic disease found in the region, while OROV causes a febrile illness sometimes accompanied by aseptic meningitis. Interesting, OROV and DENV are active in urban areas, while MAYV and YFV occur mainly in rural areas. Thirty-eight other arboviruses have been involved with febrile illness causing few or sporadic cases (Vasconcelos et al. unpublished data).

A special attention should be direct to DENV complex, due to the fact that this virus has been causing constant outbreaks in Brazil from 1990's until now. DENV (DENV-1 and DENV-4) was isolated by the first time in Brazil in 1982 in the City of Boa Vista, Roraima State from human cases as well as from Aedes aegypti mosquito's pools (Travassos da Rosa 2016). In 1986, DENV-1 was reintroduced to Rio de Janeiro (Schatzmayr et al. 1986); DENV-2 emerged in 1990, also in Rio de Janeiro (Nogueira et al. 2007), causing the first cases of hemorrhagic fever caused in the Southeast and Northeast regions (Vasconcelos et al. 1995, Figueiredo 2003). DENV-3 was introduced in 2002 in from Rio de Janeiro and spread countrywide (Nogueira et al. 2001). DENV 1 to 3 were responsible for $\approx 5$ million infections, resulting in $>15,000$ reported cases of dengue hemorrhagic fever and $\approx 1,000$ DENV-related deaths until 2007 (Teixeira et al. 2002, Dussart et al. 2012). In 2010, DENV-4 reemerged in Brazil, 28 years after it was last detected in the country (Nunes et al. 2012).

The circulation of DENV for over 30 years, along with YFV - including YFV vaccine - and other flaviviruses (Ilheus virus, Bussuquara virus, Cacipacoré virus, Rocio virus, Saint Louis Encephalitis virus), resulted in wide immunity to flavivirus, mainly in in older individuals. The occurrence of sequential infections by distinct flaviviruses has been resulting in high levels of cross reactivity in the current serological tests available, posing a great impact in the arboviral diseases surveillance and specific diagnosis.

RECENT INTRODUCTION OF NEW ARBOVIRUSES AND THE CONSEQUENCES FOR PUBLIC HEALTH IN BRAZIL

Chikungunya virus (CHIKV) is member of the Alphavirus genus (family Togaviridae) and related to MAYV in the Semliki Forest complex. CHIKV infection is associated with recurrent polyarthralgias and high rates of symptomatic infections. Clinically, CHIKV fever has a sudden onset with fever, rash, headache, joint swelling, and conjunctivitis. In 2013-2014, for the first time in Americas, CHIKV established a mosquito-human cycle and caused an outbreak, reporting more than 1,222,000 cases, mainly in Caribbean region (Leparc-Goffart et al. 2014). The first autochthonous cases of CHIKV in Brazil were confirmed in Oiapoque, Amapa State, on September 13, 2014. Seven days later, autochthonous cases were also confirmed in Feira de Santana, Bahia State. By October 18, 2014, 682 confirmed autochthonous cases had been notified to the Brazilian Ministry of Health (Teixeira et al. 2015, Nunes et al. 2015).

Molecular analysis showed that two genotypes of CHIKV were introduced independent and concomitantly in Brazil: Asian-Caribbean genotype, detected in Amapa State; and the East-CentralSouth-African (ECSA) genotype in Bahia State, but mutations that increase CHIKV transmissibility and persistence in Ae. albopictus (Tsetsarkin and Weaver 2011), were not found in the Brazilian strains. Modelling of human mobility predicted different geographic patterns of CHIKV spread risk and establishment in Brazil, from Oiapoque and Feira de Santana, and suggested a CHIKV outbreak in 98\% Brazilian territory in 2015 (Nunes et al. 2015). However, the Brazilian Ministry of Health reported less than 4,000 CHIKV cases in 2015, and only in 2016 and 2017, a major CHIKV outbreak was established (MS/SVS 2017). In a first analysis 
about CHIKV genotypes, it is suggested that ECSA genotype has been more successful in spreading throughout the country as its circulation caused a large outbreak in Rio de Janeiro State, in Southeast region (Souza et al. 2019), as well as, resulted in a replacement of the Asian genotype in Roraima and Amazonas states, in the North region (Naveca et al. 2019).

The CHIKV transmission dynamics was, however, not as predicted. In 2015, a denguelike disease was characterized and associated to a new flavivirus in Brazil. Zika virus (ZIKV) Asian genotype was officially indentified on May (Faria et al. 2016) and spread quickly over the country. By May 2016, the autochthonous transmission of ZIKV had been reported in 42 countries and territories in the Region of the Americas (Tsetsarkin et al. 2014). Despite the vectoral transmission of ZIKV, non vectoral ones were also reported and included vertical, sexual and blood transfusion transmissions, explaining the quickly spread of this virus (White et al. 2018).

The zika human clinical manifestations in Brazil were characterized by fever, myalgia, headache, conjunctival hyperemia and rash, with 3-5 days duration. In general, ZIKV has not been associated to severe disease in the past. However, the Brazilian outbreak revealed the pathogenic ZIKV potential characterized by a congenital syndrome (ZCS) and central nervous system involvement (Azevedo et al. 2016). Despite the severe microcephaly observed in some cases of ZCS, other effects such as cognitive, sensory and motor disabilities may occur (Moore et al. 2017). A review on microcephaly cases occurred during the epidemic in Brazil reported a prevalence of microcephaly of $2.3 \%$ among all pregnancies and showed that and ZIKV infection at the first trimester was associated with higher risk to congenital anomalies (Coelho and Crovella 2017).

A retrospective study on the French Polynesian outbreak occurred in 2014 and based on the
Brazilian experience, showed the occurrence of Guillain-Barré syndrome (GBS), an autoimmune disorder causing acute or subacute flaccid paralysis, for the first time (Musso and Gubler 2016).Moreover, in adults, ZIKV was also detected in patient showing encephalomyelitis associated with immunoactivation (Galliez et al. 2016) and in two fatal cases from patients with lupus and severe thrombocytopenia. Interesting, none ZIKV genome mutation was associated to those severe cases 183 (Azevedo et al. 2016, Faria et al. 2016).

\section{ZIKV AND CHIKV NEXT STEPS}

Once CHIKV and ZIKV were introduced at the same period, epidemiological data suggested that ZIKV was more efficiently transmitted despite the high viremia presented by CHIKV infections, delaying the latter outbreak in Brazil. In 2016, tail end of the Zika epidemic was displaced by a chikungunya epidemic, mainly in northeast region of Brazil (Magalhães et al. 2017). One of the hypothesis for this scenario is the viruses competition into mosquito vectors. In spite of the fact mosquito vectors may be infected by different arboviruses, studies with Ae. aegypti co-infected with different DENV serotypes showed an displacement of DENV-1 by DENV-4, probably due to competition between serotypes for the cell receptors at the midgut cells in co-infected mosquitoes leading to a drastically different transmission potential (Vazeille et al. 2016). Furthermore, assymptomatic and oligoassymptomatic ZIKV cases may have naturally immunized the Brazilian population, allowing the CHIKV emergence. Differently from what was observed in the northeast-southeastmidwest regions, CHIKV and ZIKV spread to North region in later time. From 2015 to 2018, the Amazon region has reported an increase from 3\% to $10 \%$ of CHIKV cases and $6 \%$ to $15 \%$ of ZIKV in Brazil. However just few severe cases were reported in Amazon region (MS/SVS 2017) 
To predict what the future holds to CHIKV and ZIKV in Brazil, we may not forget the impact of the introduction of an exotic arbovirus in our ecosystem, such as occurred with YFV. Studies have shown that the origin of YFV in the Americas was from Africa, along with Ae. aegypti, in the bilges of sailing vessels during the slave trade, approximately 300-400 years ago. Subsequently to devastating urban outbreaks within port cities on both the east (or Atlantic Ocean) and west (or Pacific Ocean) coasts of South America, the virus established a sylvatic enzootic cycle within the Amazon, Araguaia-Tocantins, and Orinoco river basins vectored by Haemagogus and Sabethes mosquitoes (Bryant et al. 2007).

Regardless of the Yellow fever vaccine program's success preventing the virus transmission in urban centers since 1942, every 6-8 years, a new epizootic/epidemic rises in Brazil (Monath and Vasconcelos 2015). The last epizootic/epidemic reported in the country was in 2016-2018 (MoreiraSoto et al. 2018) and it was considered the largest YF epidemic in decades, involving non-human primates, as well as, 1,376 human cases with 483 death until jun/2018 in several states (MS/SVS 2017).

Due to the well characterized sylvatic cycle of CHIKV and ZIKV in the old world, as well as the evidence of natural ZIKV infection in neotropical no human primates in Brazil (Terzian et al. 2018), along with the YF epidemiology, it may be suggested that those newly introduced viruses may adapt to different Brazilian natural environments. If both viruses will establish enzootic cycles in nature and, in the future, will be responsible for jungle outbreaks, it is a question that remains to be answered.

\section{ACKNOWLEDGMENTS}

In memory of Amelia P. A. Travassos da Rosa and all the restless dedication and knowledge passed to our generation of arbovirologist from Evandro Chagas Institute. A Special thanks to Flavia Barreto dos Santos for scientific support. We are grateful to Conselho Nacional de Desenvolvimento Científico e Tecnológico (CNPq processes 306581/2016-7 and 303999/2016-0) for financial support.

\section{AUTHOR CONTRIBUTIONS}

Both authors contributed equally to produce this review.

\section{REFERENCES}

AZEVEDO RS ET AL. 2016. Zika virus epidemic in Brazil. I. Fatal disease in adults: Clinical and laboratorial aspects. J Clin Virol 85: 56-64.

BRYANT JE, HOLMES EC AND BARRETT ADT. 2007. Out of Africa: A Molecular Perspective on the Introduction of Yellow Fever Virus into the Americas. PLoS Pathog 3(5): 1-6.

DARWISH M, GORMAN B AND KALUNDA M. 1895. rthropod-borne and rodent-borne viral diseases World Health Organ Tech Rep Ser 719: 1-116.

DÉGALLIER N, TRAVASSOS DA ROSA APA, VASCONCELOS PFC, HERVER JP, SÁ FILHO GC, TRAVASSOS DA ROSA JF, TRAVASSOS DA ROSA ES AND RODRIGUES SG. 1992. Modifications of arbovirus transmission in relation to construction of dams in Brazilian Amazonia. Pub Heth Amazon 44: 124-135.

DIRZO RAND RAVEN P H. 2003. Global state of biodiversity loss. An Rev Env Res 28(1): 137-167.

DUSSART P ET AL. 2012. Clinical and virological study of dengue cases and the members of their households: The multinational denframe project. PLoS Negl Trop Dis 6(1): e1482.

FARIA NR ET AL. 2016. Zika virus in the Americas: Early epidemiological and genetic findings. Science 352(6283): 345-349.

GALLIEZ RM ET AL. 2016. Zika virus causing encephalomyelitis associated with immunoactivation. Open Forum Infect Dis 3(4): 203.

LEPARC-GOFFART I, NOUGAIREDE A, CASSADOU S, PRAT C AND DE LAMBALLERIE X. 2014. Chikungunya in the Americas. Lancet 383(9916): 514.

MAGALHAES T ET AL. 2017. Zika virus displacement by a chikungunya outbreak in Recife, Brazil. PLoS Negl Trop Dis 26: 1-25.

MONATH TP AND VASCONCELOS PFC. 2015. Yellow fever. J Clin Virol 64: 160-173. 
MOREIRA-SOTO A ET AL. 2018. Evidence for multiple sylvatic transmission cycles during the 2016-2017 yellow fever virus outbreak, Brazil. Clin Microbiol Infect 9(24): 1019.

MS/SVS. 2017. Emergência epidemiológica de febre amarela no Brasil, no período de dezembro de 2016 a julho de 2017. Boletin Epidemiológico 48(28): 1-22.

MUSSO D AND GUBLER DJ. 2016. Zika virus. Clin Microbiol Rev 29(3): 487-524.

NAVECA FG ET AL. 2019. Genomic, epidemiological and digital surveillance of Chikungunya virus in the Brazilian Amazon. PLoS Negl Trop Dis 3(13): 7065.

NOGUEIRA RM, MIAGOSTOVICH MP, DE FILIPPIS AM, PEREIRA MA AND SCHATZMAYR HG. 2001. Dengue virus type 3 in Rio de Janeiro, Brazil. Mem Inst Oswaldo Cruz 96(7): 925-926.

NOGUEIRA RMR, DE ARAÚJO JMG AND SCHATZMAYR HG. 2007. Dengue viruses in Brazil, 1986-2006. Rev Panam Salud Publica 22(5): 358-363.

NUNES MR ET AL. 2012. Phylogeography of dengue virus serotype 4, Brazil, 2010-2011. Emerg Infect Dis 18(11): 1858-1864.

NUNES MR ET AL. 2015. Emergence and potential for spread of Chikungunya virus in Brazil Emergence and potential for spread of Chikungunya virus in Brazil. BMC Med 30(13): 102.

SCHATZMAYR HG, NOGUEIRA RMR AND TRAVASSOS DA ROSA APA. 1986. An outbreak of dengue virus at Rio de Janeiro - 1986. Mem Inst Oswaldo Cruz 81(2): 245-246

SOUZA TML ET AL. 2019. Emergence of the EastCentral-South-African genotype of Chikungunya virus in Brazil and the city of Rio de Janeiro may have occurred years before surveillance detection. Sci Rep 1(9): 2760

TADEU L AND FIGUEIREDO M. 2003. Dengue in Brazil: Past, Present and Future Perspective Brazilian flaviviruses. Dengue Bulletin 27(1): 25-33.

TEIXEIRA MDA G, BARRETO ML, COSTA MDA C, FERREIRA LD, VASCONCELOS PF AND CAIRNCROSS S. 2002. Dynamics of dengue virus circulation: A silent epidemic in a complex urban area. Trop Med Int Health 7(9): 757-762.

TEIXEIRA MG, ANDRADE A, COSTA MC, CASTRO J, OLIVEIRA F, BORGES C, MAIA M, SANTANA E, NUNES BT AND VASCONCELOS PFC. 2015.
Chikungunya outbreak in Brazil by African Genotype. Emerg Infect Dis 21: 906-908.

TERZIAN ACB ET AL. 2018. Evidence of natural Zika virus infection in neotropical nonhuman primates in Brazil. Sci Rep 8(1): 16034.

TRAVASSOS DA ROSA APA, TRAVASSOS DA ROSA JF, HERVÉ JP, VASCONCELOS PFC, DÉGULER N AND RODRIGUES SG. 1992. Arboviruses in Serra Norte, Carajás, Pará, Brasil. Ciencia e Cultura, Publ Health Amazon 44(2/3): 158-161.

TRAVASSOS DA ROSA APDA. 2016. The history of Arbovirology at Instituto Evandro Chagas, Belém, Pará, Brazil, from 1954 to 1998. Rev Pan-Amazonica Saúde 7: 61-70.

TSETSARKIN KA ET AL. 2014. Multi-peaked adaptive landscape for chikungunya virus evolution predicts continued fitness optimization in Aedes albopictus mosquitoes. Nat Commun 5: 4084.

TSETSARKIN KA AND WEAVER SC. 2011. Sequential adaptive mutations enhance efficient vector switching by chikungunya virus and its epidemic emergence. PLoS Pathog 7(12): 2412.

VASCONCELOS PF, DE MENEZES DB, MELO LP, PESSO ET, RODRIGUES SG, DA ROSA ES, TIMBÓ MJ, COELHO IC, MONTENEGRO F AND TRAVASSOS DA ROSA JF. 1995. A large epidemic of dengue fever with dengue hemorrhagic cases in Ceará State, Brazil, 1994. Rev Inst Med Trop Sao Paulo 37(3): 253-255.

VASCONCELOS PF, TRAVASSOS DA ROSA AP, RODRIGUES SG, TRAVASSOS DA ROSA ES, DÉGALLIER N AND TRAVASSOS DA ROSA JF. 2001. Inadequate management of natural ecosystem in the Brazilian Amazon region results in the emergence and reemergence of arboviruses. Cad Saude Publica 17 Suppl: 155-164.

VASCONCELOS PFC, TRAVASSOS DA ROSA APA, DEGALLIER N, TRAVASSOS DA ROSA JF AND PINHEIRO F. 1992. Clinical and ecoepidemiological situation of human arboviruses in Brazilian Amazonia. Publ Health Amazon 44(2/3): 117-124.

VAZEILLE M, GABORIT P, MOUSSON L, GIROD R AND FAILLOUX AB. 2016. Competitive advantage of a dengue 4 virus when co-infecting the mosquito Aedes aegypti with a dengue 1 virus. BMC Infectious Diseases 16: 318.

WHITE SL ET AL. 2018. Infectious Disease Transmission in Solid Organ Transplantation. Transplant Direct 5(1): e416. 